\title{
Indústria da beleza: uma abordagem sócio-antropológica do culto ao corpo na cultura contemporânea
}

Ana Lúcia de Castro*

Resumo: $\mathrm{O}$ artigo problematiza a obsessão pela aparência expressa no impressionante crescimento da indústria da beleza. Partindo-se do pressuposto de que o corpo configura-se como importante território de construção de identidades, apresenta-se dados relativos ao desempenho de setores econômicos ligados à indústria da beleza - com destaque para cosméticos e moda - em busca dos contornos da materialidade do culto ao corpo, traço cultural que atravessa a sociedade contemporânea como um todo e envolve um conjunto de técnicas, habilidades e consumo de bens materiais para sua realização.

Palavras-chave: culto ao corpo, identidades, indústria da beleza, cultura contemporânea.

Abstract: The article discusses the obsession with appearance expressed in the impressive growth of the industry of beauty. Based on the assumption that the body has become an important area for the construction of identities, it presents data on the performance of economic sectors related to the beauty industry - with emphasis on cosmetics and fashion - in search of the contours of the materiality of cult of the body, cultural trait that crosses contemporary society as a whole and involves a set of techniques, skills, and consumption of material goods for their achievement.

Keywords: body cult, identities, beauty industry, contemporary culture.

* Doutora pelo Programa de Pós-Graduação em Ciências Sociais da Universidade Estadual de Campinas (2001). Atualmente é professora efetiva da Universidade Estadual Paulista Júlio de Mesquita Filho. 


\section{Introdução}

Este artigo discute a obsessão pela aparência expressa no impressionante crescimento da indústria da beleza. Partindo-se do pressuposto de que o corpo configura-se como importante território de construção de identidades, apresenta-se dados relativos ao desempenho de setores econômicos ligados à indústria da beleza - com destaque para cosméticos e moda - em busca dos contornos da materialidade do culto ao corpo, traço cultural que atravessa a sociedade contemporânea como um todo ${ }^{1}$ e envolve um conjunto de técnicas, habilidades e consumo de bens materiais para sua realização.

Ao abordar a dimensão material de um fenômeno comportamental, como o culto ao corpo, este artigo inspira-se, fortemente, nas proposições de Raymond Williams (1979), relativas ao entendimento da cultura. Aproximando-se bastante de uma perspectiva antropológica, o autor inglês propõe a noção de cultura comum ou ordinária, para se referir ao fato de que o termo envolve a experiência cotidiana, bem como o seu compartilhamento, congregando os indivíduos em sociedade, unidos pelas experiências comuns vivenciadas ativamente. Além disso, o autor aponta para a idéia de que o termo diz respeito à produção de significados e valores, envolvendo relações entre estruturas e instituições sociais diversas.

Um dos principais legados teóricos dos estudos culturais ingleses reside na preocupação em lançar luz ao sujeito e suas possibilidades de apropriações e resignificações dos sentidos hegemonicamente construídos - que mais tarde veio a ser denominado como o espaço de uma agência individual ${ }^{2}$. Ao trabalharem mais sistematicamente - embebidos pela influência do pensamento gramsciano - com a idéia de "resistência", os autores ligados a esta vertente sugerem que o indivíduo não é apenas reprodutor, de maneira condicionada, das estruturas e organização social e, assim, recuperam a idéia de uma correspondência dialética entre os agentes e as instituições. Os temas da recepção

${ }^{1} \mathrm{O}$ culto ao corpo experimentado nas sociedades contemporâneas é decorrente de um processo societário de longa duração, relativo à expansão da modernidade. Como marcos importantes deste processo, podemos destacar a difusão dos espelhos; a invenção da fotografia; a ampliação dos espaços públicos vida social, sobretudo nas esferas de lazer e consumo,

2 Na história do pensamento social, muitos são os exemplos em que podemos identificar a marca desta preocupação sobre os limites da ação individual e da subjetividade frente ao constrangimento e aos limites impostos pelas estruturas objetivamente manifestas pelas instituições sociais. O processo de individualização é sistematizado na reflexão de Norbert Elias (1994), que desenvolve esclarecedora reflexão acerca da balança nós-eu. O conceito de habitus foi cunhado por Pierre Bourdieu (2007) como ferramenta para reflexão acerca do filtro subjetivo exercido pelos indivíduos no contato inevitável com as estruturas socialmente construídas. Anthony Giddens (1997), com a noção de reflexividade também está buscando lançar luz ao sujeito individual na relação com as macro-estrutras e instituições sociais. 
Indústria da beleza: uma abordagem sócio-antropológica do culto ao corpo na cultura contemporânea

dos meios massivos, dos estilos de juventude, do corpo, dos conflitos raciais, das relações de gênero, da subjetividade, da identidade e do consumo, passaram a ser trabalhados a partir de universos empíricos claramente recortados e de uma total revisão da noção de ideologia e da metáfora marxista acerca da superestrutura como reflexo da base material. ${ }^{3}$

Nesta linha, mais do que como produto, a cultura é vista como produção material, portanto, como modo de vida, ou seja, prática social que articula instituições carrega implicações políticas, movimenta montantes financeiros, promove e contesta valores e idéias. A abordagem de diferentes tipos de instituições e formações pelas quais a cultura se faz produzir, distribuir e divulgar é bastante promissora, ao propiciar a análise das relações entre processos materiais e elaborações de significações simbólicas.

É partindo destes pressupostos - procurando contribuir para a compreensão da relação entre economia e cultura - que propomos a presente reflexão, buscando apresentar a dimensão material de um dos traços culturais mais significativos da cultura contemporânea: a obsessão contemporânea pela construção da aparência que se expressa na busca por um padrão corporal estabelecido socialmente. Para tanto, discutiremos inicialmente a relação corpo e sociedade, apontando para o papel do corpo como suporte da cultura; em seguida, abordaremos a evolução do desempenho financeiro dos setores econômicos envolvidos com a produção da aparência - sobretudo o setor de cosméticos e da moda. A hipótese que orienta esta reflexão relaciona a obsessão com a construção da aparência com a complexificação, fragmentação e instabilidade que marcam a condição contemporânea.

\section{Corpo: produto e produtor da cultura}

As ciências sociais contam com vários estudos que demonstram a forma como o corpo se configura em símbolo de uma cultura, espaço em que se projetam códigos de identidade e de alteridade, sendo os usos que dele se faz, associados ao vestuário, ornamentos e pinturas corporais, indicativos de universos simbólicos, capazes de nos ajudar a melhor compreender o mundo que o envolve. Vários trabalhos etnográficos nos dão conta do papel central ocupado pelo corpo para definição de identidades e elos de pertença a determinados grupos em sociedades não ocidentalizadas. Escarificações, tatuagens, pinturas e adornos corporais são

\footnotetext{
3 Sobre a revisão da relação entre infra-estrutura e super-estrutura no pensamento marxista, Raymond Williams (1979) revê a idéia de determinação, elucidando sua raiz etmológica e demonstrando os equívocos de pensá-la apenas numa direção. Como alternativa, sugere a idéia de uma correspondência entre as instâncias da super e infra-etrutura.
} 
Ana Lúcia de Castro

recorrentemente identificados por estudiosos como recursos de marcação identitária e, de modo mais geral, da condição social. ${ }^{4}$

Vale lembrar, antes de tudo, as reflexões de Durkheim (1984) e Mauss (2003), que afirmam a proeminência do social sobre o individual, postulando a origem social de todo ato classificatório e descartando explicações psicologizantes - que partem da idéia de que os homens classificam as coisas e o mundo por uma necessidade interna de seu entendimento individual. Para estes autores, trata-se de encontrar o lugar de onde se originam os sistemas classificatórios e, ao mesmo tempo, explicar a lógica interna que preside a formação, organização, o processamento e a atualização dos mesmos. Assim, o que caracteriza as referidas classificações é que as idéias estão nelas organizadas de acordo com o modelo fornecido pela sociedade.

Mary Douglas (1976) contribuirá para a reflexão aqui proposta ao demonstrar a evidência do simbolismo social no corpo humano. Segundo a autora, os rituais públicos sobre o corpo evidenciam interesses coletivos, não pessoais, pois se o corpo é próprio do indivíduo que participa do ritual, o que está sendo gravado na carne humana é a imagem da sociedade. (1976:143) Haveria uma espécie de estoque de símbolos criados socialmente que apareceriam nos rituais que, por sua vez, representariam as formas de relações sociais que permitiria aos indivíduos a compreensão de sua própria sociedade. Nas palavras da autora:

“Como é verdade que tudo simboliza o corpo, então também é verdade que o corpo simboliza todo o resto. A partir deste simbolismo, que de camadas em camadas de significado interior remete à experiência do eu com seu corpo, o sociólogo encontra justificativa para retirar algumas amostras do 'insight' sobre a experiência do eu na sociedade. (Douglas, 1976:150).

Na mesma linha temos Marcel Mauss (2003:401) que, ao cunhar o conceito de técnicas corporais define como “(...) as maneiras como os homens, sociedade por sociedade, de uma forma tradicional, sabem servir-se de seu corpo (...)". Chamando a atenção para a compreensão das práticas corporais, suas origens e implicações sociais, o autor aponta para o corpo como o arcabouço simbólico da sociedade: signo das representações coletivas.

Contribuição importante também nos é fornecida por Pierre Bourdieu (1988), ao demonstrar que a linguagem corporal é marcadora pela distinção social. Para o autor, a comunicação corporal ocupa uma posição fundamental na sua argumentação, enquanto que a sua construção teórica destaca o consumo alimentar, cultural e a forma de apresentação (incluindo o consumo de vestuário, artigos de beleza, higiene e de cuidados e manipulação do corpo em geral) como as três mais importantes maneiras de distinguir-se, pois são reveladoras das

${ }^{4}$ Os registros etnográficos são dispersos e ainda está por ser realizada a tarefa de reuni-los e discuti-los em um só trabalho. Podemos destacar os trabalhos de MULLER,1992; BENEDICT,s/d; MEAD,1979 e MAUSS, 2003.

Latitude, vol. 4, nº 1, pp. 54-73, 2010. 
Indústria da beleza: uma abordagem sócio-antropológica do culto ao corpo na cultura contemporânea

estruturas mais profundas determinadas e determinantes do habitus ${ }^{5}$. Nas palavras do autor:

“O corpo é a mais irrecusável objetivação do gosto de classe, que manifesta de diversas maneiras. Em primeiro lugar, no que tem de mais natural em aparência, isto é, nas dimensões (volume, estatura, peso) e nas formas (redondas ou quadradas, rígidas e flexíveis, retas ou curvas, etc...) de sua conformação visível, mas que expressa de mil maneiras toda uma relação com o corpo, isto é, toda uma maneira de tratar o corpo, de cuidálo, de nutri-lo, de mantê-lo, que é reveladora das disposições mais profundas do habitus". (Bourdieu, 1988:188)

As reflexões de Michel Foucault (1979) muito impactaram, e ainda impactam, sobre os estudos do corpo no interior das ciências sociais. Em seu trabalho, o saber é apontado como importante mecanismo de poder e forma de garantir o desenvolvimento da sociedade industrial. Foucault, ao desenvolver o conceito de "biopoder" como uma tecnologia disciplinadora de controle utilitarista do corpo, revela que as tecnologias disciplinares tinham no corpo o foco do poder cuja principal finalidade é o adestramento e a docilização dos indivíduos para extrair deles as forças necessárias aos interesses do capital. É o corpo totalmente administrado, a serviço do funcionamento da grande engrenagem social.

Das reflexões foucaultianas derivaram as teorias sobre o "homemmáquina": aquele que teria seu corpo como um produto da manipulação científica (Rouanet, 2003); bem como sobre o "pós-humano", a possibilidade do ser humano ter avançado na escala da evolução da espécie, sendo agora um ser de outro tipo, do ponto de vista cognitivo, cerebral e psicológico - portadores de um novo sensorium, no sentido benjaminiano - habitariam o planeta, como se fôssemos membros de uma última geração de humanos. (Kahn, 2003)

Elucubrações à parte, o que podemos reter do conjunto de contribuições das ciências sociais sobre o corpo é o fato de que o corpo, suas práticas e representações, só podem ser entendidos se conectados à dinâmica social, ou seja, entender o que uma sociedade faz com seus corpos, o que neles é por ela valorizado ou desvalorizado.

A preocupação com a aparência está ligada à cisão, própria da modernidade, entre o ser e o parecer. Diferentemente de outros momentos históricos, as sociedades modernas impõem aos indivíduos a necessidade de definirem suas identidades, não mais pré-determinadas pela tradição e pelo costume, como nos contextos tradicionais. Nas sociedades contemporâneas, o indivíduo deve repensar-se e redefinir sua identidade cada vez mais

5 O conceito de habitus, cunhado por Bourdieu, refere-se ao processo de interiorização/internalização das regras objetivas, o que ocorre de forma subjetiva. É conformador e orientador da ação na medida em que é produto das relações sociais e tende a assegurar a reprodução dessas mesmas relações objetivas que o engendram. 
frequentemente (Hall, 2000), levando a uma condição em que tudo o que diz respeito à construção da aparência cresce em importância.

Segundo Anthony Giddens (1997), no contexto da modernidade, o self entendido como auto-identidade - é produto de um projeto reflexivo e o indivíduo o principal responsável por ele. Nesta perspectiva, a reflexividade joga importante influência sobre a dinâmica da vida moderna, uma vez que "(...) diz respeito à possibilidade de a maioria dos aspectos da atividade social, e das relações materiais com a natureza, serem revistos radicalmente à luz de novas informações ou conhecimentos." (Giddens, 1997: 18).

Percebe-se, claramente, um esforço do autor de pôr em relevo a efemeridade e multiplicidade de espaços e instituições sociais que marcam a condição moderna, situando o indivíduo como ser atuante neste processo. Diante da multiplicidade e segmentação de cenários que constituem a vida social, os estilos de vida configuram-se em espaços, ou ambientes de ação específicos, denominados pelo autor de setores de estilo de vida.

"Em parte devido à existência de múltiplos ambientes de ação, as escolhas e atividades de estilo de vida tendem com grande freqüência a ser segmentárias para o indivíduo: os modos de ação seguidos num contexto poderão variar mais ou menos substancialmente em relação aos adotados em outros contextos".

(Giddens, 1997:77-78)

O constante processo de redefinição do self implica na construção de um estilo de vida, no qual o corpo assume papel central: os regimes do corpo, como dietas e fitness, bem como a organização da sensualidade na modernidade tardia tornam-se abertos a uma contínua atenção reflexiva, sobre o pano de fundo da pluralidade de escolha.

Deste modo, a construção da aparência - envolvendo adornos, posturas e modos de vestir - passa a depender cada vez mais das formas e volume corporais e torna-se elemento central no projeto reflexivo do self. Daí o evidente crescimento da indústria da beleza, que coloca o corpo como elemento central na busca de sentidos e referências mais estáveis, talvez por constituir-se, supostamente, em único domínio ainda controlável pelos indivíduos. Pensar a obsessão atual pela construção da aparência como espécie de resposta à instabilidade, fragmentação e efemeridade que marcam a vida social nos ajuda a compreender a centralidade assumida pelo culto ao corpo na cultura contemporânea. Centralidade esta que pode ser atestada por uma observação mais atenta do cotidiano que nos cerca, assim como pela análise da evolução dos setores que compõem a indústria da beleza, como demonstrado a seguir.

\section{O culto ao corpo em números: Evolução recente da indústria da beleza}

Ao apontarmos a dimensão material de um fenômeno estudado sob o ponto de vista comportamental, partimos do pressuposto de que as manifestações culturais constituem-se no embricamento das duas dimensões: simbólica e 
Indústria da beleza: uma abordagem sócio-antropológica do culto ao corpo na cultura contemporânea

material. Trata-se, assim, de não perder de vista os nexos entre o campo das elaborações simbólicas e a dimensão material das mesmas, onde se processam as relações sociais entre os agentes e as instituições econômicas.

No decorrer da última década do século vinte e nestes primeiros anos do corrente século, todos os setores da economia envolvidos com a produção e/ou manutenção da beleza vêm experimentando significativo crescimento. Os dados apresentados pela $\mathrm{ABIHPEC}^{6}$ não deixam dúvidas acerca do impressionante desempenho do setor responsável pela fabricação dos produtos de higiene pessoal, cosméticos e perfumaria, um dos principais filões da indústria da beleza. Em termos de faturamento, no período de 1991 a 1995, o setor acumula um crescimento de $126,6 \%$, passando de 1,5 bilhões de dólares, para 3,4 bilhões de dólares. Como demonstra o gráfico 1 , a tendência ao forte crescimento continua se mantendo na segunda metade dos anos 90, adentrando na década de 2000. O faturamento líquido salta de $\mathrm{R} \$ 4,9$ bilhões, em 1996, para $\mathrm{R} \$ 8,3$ bilhões em 2001, alcançando a marca dos $\mathrm{R} \$ 17,3$ bilhões em 2005 . Na primeira metade da corrente década (entre 2001 e 2005), o crescimento médio do faturamento do setor foi de 10,7\% ao ano

Para melhor compreensão da dimensão do crescimento deste setor, é necessário contextualizá-lo na economia global, comparando-o com o Produto Interno Bruto e com o desempenho de todos os setores industriais. $\mathrm{O}$ gráfico 2 revela a impressionante performance do setor em estudo no decorrer da década de 90, com níveis de crescimento acima da indústria como um todo e do Produto Interno Bruto (PIB). A queda do PIB em 1996 pode ser explicada pelas políticas de contenção de consumo implementadas pelo Governo Federal neste ano, a partir do qual o setor em foco experimenta crescimento, ainda que em proporções bem menores. Mesmo o pior ano - 1998 - conhece um menor, mas significativo incremento $(6,8 \%)$, que pode ser explicado pelo reflexo da crise dos países asiáticos, que fez a indústria nacional declinar em - 0,1\%. Com a queda o PIB alcançou uma taxa de crescimento inferior a meio ponto percentual, a mais baixa desde 1992. O crescimento superior em relação ao PIB permaneceu nos anos 2000. Entre 2001 e 2005, segundo a ABIHPEC, enquanto o crescimento médio do setor foi de $10,7 \%$ ao ano, o PIB cresceu, anualmente, $2,2 \%$.

O nível de emprego constitui-se num ótimo indicador para explicar o desempenho do setor e, embora apresente algumas limitações, pode ser utilizado como referência. $\mathrm{O}$ fato de um setor industrial apresentar queda no nível de emprego não implica, necessariamente, em queda de produção e/ou faturamento, porém, o crescimento do nível de emprego implica em elevação da produção.

Se a tendência da indústria como um todo, desde 1985, foi de queda sistemática do nível de emprego, o setor em foco apresentou tendência oposta, crescendo constantemente, com uma ligeira queda em 1992 e 1997 - que pode ser atribuída ao impacto do Plano Collor e da crise asiática. Em 1999 empregou 52,41\% acima da média de 1985, enquanto a indústria total empregou, no mesmo ano, quase 50\% a menos do que empregava em 1985 (conforme gráfico 3).

${ }^{6}$ Associação Brasileira da Indústria de Higiene Pessoal, Perfumaria e Cosméticos 
O gráfico 4 aponta uma recomposição da participação de cada segmento no setor higiene pessoal, perfumaria e cosméticos. Os itens considerados mais próximos da categoria supérfluos - perfumaria e cosméticos - aumentaram sua participação no faturamento do setor, enquanto higiene pessoal, mais próximo à categoria de bens de primeira necessidade, reduz sua participação, o que indica uma mudança de comportamento do consumidor, que passa a valorizar e incorporar esses itens em sua cesta de consumo.

O Brasil é o quinto mercado mundial de cosméticos, o quarto em xampus e o terceiro em condicionadores, embora, segundo os fabricantes do produto, o consumo per capita ainda seja baixo. A indústria brasileira tem concentrado seus investimentos nas chamadas marcas globais, ou seja, nos produtos que também são comercializados no exterior. As principais empresas que vêm redirecionando seus investimentos a fim de ampliar a penetração de produtos como xampus, condicionadores e cremes para tratamento da pele no exterior são Avon, Protector \& Gamble, Gessy Lever e Colgate-Palmolive.7 Em consonância com a tendência do setor como um todo, o faturamento da Avon - líder do mercado nacional de cosméticos - cresceu bastante na década de 90, conforme explicitado no gráfico 5 .

O Brasil, que historicamente ocupava o $18^{\circ}$ lugar no ranking mundial da Avon, desde 1996 passou a ocupar a segunda posição nas vendas desta marca.

O faturamento mundial da indústria de cosméticos cresceu no período de 1990 a 1998 em R \$167 bilhões. Na Europa ocidental o valor do faturamento do setor em 1998 foi de US\$ 64 bilhões - crescimento de 15\% em relação a 1990. Na região do NAFTA, o crescimento foi de $30 \%$ e no Japão de $21 \%$. Essas três regiões, somadas, foram responsáveis por $75 \%$ do volume de vendas no setor em 1998.

O mercado brasileiro representa $4 \%$ do mercado mundial, participação muito superior à que caracteriza mercados de outros tantos produtos $(1 \%$ a $2 \%)$. Como mercado consumidor, o Brasil saltou da sexta posição ocupada em 2000 (atrás de EUA, Japão, Alemanha, França e Reino Unido) para a terceira, ficando, em 2007, atrás apenas dos EUA e Japão ${ }^{8}$.

As grandes empresas internacionais do setor se organizam, basicamente, de duas maneiras: grandes conglomerados, que atuam em diferentes setores da economia e empresas com atividades concentradas em cosméticos e, em alguns casos, também em perfumaria. Dentre as empresas do setor com atuação diversificada, destacamos o exemplo da Unilever, empresa anglo-holandesa cujo faturamento em 2001 ultrapassou o patamar dos US\$ 51 bilhões. Está no segmento de higiene pessoal, incluindo aí os produtos cosméticos (24\% da receita), alimentos $(23 \%)$, higiene e limpeza (20\%), óleos e margarinas $(17 \%)$, sorvetes e bebidas $(15 \%)$ e outros (1\%). ${ }^{9} \mathrm{O}$ grupo administra algumas das principais marcas do setor cosmético: Rexona, Seda, Vasenol e Vinólia, ao lado de marcas consagradas no

${ }^{7}$ Folha de São Paulo, Caderno Negócios, 11/08/97

8 Conforme depoimento concedido pelo Sr. João Carlos Basílio, presidente da ABIHPEC, em fevereiro de 2007.

${ }_{9}^{9}$ Os dados relativos aos faturamentos das empresas do setor foram extraídos de Garcia (2005). 
Indústria da beleza: uma abordagem sócio-antropológica do culto ao corpo na cultura contemporânea

setor de alimentação e higiene, como Arisco, Knorr, Maisena, Kibon, Becel, Ades, Comfort, Cliff, Clear, Fofo, Brilhante e Omo.

Dentre as empresas que têm como estratégia a atuação concentrada em cosméticos e perfumaria, podemos destacar o grupo francês L'Oreal, que alcançou um faturamento mundial em 2001 de US\$ 13,6 bilhões e é proprietário (ou licenciado) de diversas marcas internacionais, entre elas L'Oreal Paris, Biotherm, Giorgio Armani, Helena Rubinstein, Laboratories Garnier, Lancôme, Maybelline, Ralph Lauren, Cacharel, entre outras - marcas estabelecidas mundialmente. Por concentrar suas atividades produtivas e tecnológicas na indústria de cosméticos, as empresas do grupo oferecem, em geral, produtos mais sofisticados e diferenciados.

Além disso, combinam arrojadas estratégias tecnológicas com uma atuação mundial. O faturamento do grupo advém de diferentes regiões: $49 \%$ é oriundo da Europa Ocidental, $32 \%$ da América do Norte e os $20 \%$ restantes distribuídos pelas outras partes do globo. Além disso, a empresa vem empreendendo uma política de aquisições com o intuito de consolidar sua posição nos diversos mercados nacionais. Somente no Mercosul ${ }^{10}$, por exemplo, de acordo com informações corporativas, a empresa adquiriu em janeiro de 2000, na Argentina, a Miss Yang S.A. e em 2001, no Brasil, a Colorama.

Uma significativa distinção entre este tipo de empresa e os grandes conglomerados refere-se à forma de comercialização. Diferentemente das empresas diversificadas que comercializam seus produtos em supermercados e hipermercados, as empresas de atuação concentrada na indústria de perfumaria e cosméticos adotam estratégias de comercialização de seus produtos através de lojas especializadas. Cabe destacar uma importante variação dessa estratégia concentrada: a comercialização de produtos por meio das vendas diretas (door-todoor). Os principais casos desta variante são estadunidenses: Avon, cujo faturamento em 2001 foi de US\$ 5,9 bilhões; Mary Kay, que obteve receitas totais de US\$ 1,3 bilhão em 2001 e Nu Skin, que faturou US\$ 880 milhões em 2001.

Quanto ao desempenho do setor de alimentos dietéticos, outro importante filão do mercado da boa forma e da beleza, vale salientar que, segundo dados da Associação Brasileira das Indústrias de Alimentos Dietéticos (ABIAD, 1996), em dezembro de 1991, os alimentos dietéticos eram consumidos por $55 \%$ da população brasileira, a maioria composta por mulheres (60\%), na faixa de 18 a 34 anos $(69 \%)$ e pertencentes à classe $\mathrm{A} / \mathrm{B}(63 \%)$.

Os dados referentes ao faturamento da indústria de alimentos dietéticos apontam que este segmento da indústria alimentícia vem crescendo fortemente. Em 1990, porém, o setor vive sua primeira crise, experimentando queda significativa no faturamento, mas, em 1991, retoma o patamar de 200 milhões de dólares, relativo a 198911 e, em 1994, salta para U\$\$ 336 milhões, enquanto o número de fabricantes desses produtos no Brasil cresceu de 12, em 1991, para 40,

${ }^{10}$ Mercado Comum do Sul. Tratado de livre comércio entre a Argentina, Brasil, Paraguai e Uruguai.

11 Conforme dados divulgados pelo Guia Brasileiro de alimentos e bebidas dietéticos, 1992. 
em 199412. De acordo com a ABIAD, entre 1991 e 2000, o faturamento dos fabricantes de produtos light e diet foi multiplicado por dez. ${ }^{13}$

O faturamento do setor de alimentos dietéticos cresceu em 420,47\%, no período de 1993 a 1998, sendo que o segmento sobremesas deteve a variação mais significativa $(640 \%)$. Os refrigerantes constituem o segmento com maior participação no faturamento do setor: $43 \%$. O gráfico 6 ilustra o crescimento do faturamento de cada segmento que compõe o setor de alimentos dietéticos.

No setor serviços, as academias de ginástica e as clínicas de cirurgia plástica são as instituições mais significativas do mercado de produção da beleza. Segundo o Sindicato dos Estabelecimentos de Esportes Aquáticos, Aéreos e Terrestres do Estado de São Paulo (SEEATESP), embora não haja cifras precisas, estima-se que o mercado da malhação movimenta $R \$ 2$ bilhões ao ano no país. ${ }^{14} \mathrm{O}$ Brasil já é o maior mercado de academias de ginástica na América Latina e o segundo maior em número de academias no mundo. Se contava com aproximadamente $4 \mathrm{mil}$ academias em 1999, hoje possui mais de 7 mil, freqüentadas por mais de 2,1 milhões de pessoas. Mais de $50 \%$ delas estão na região sudeste, principalmente no eixo Rio-São Paulo, 25\% concentram-se na região Sul e os outros $25 \%$ dividem-se entre as regiões Norte, Nordeste e Centro-Oeste. A cidade onde há o maior crescimento atual é Brasília.

A cirurgia plástica é importante atividade pertinente ao tema em debate, uma vez que o Brasil é, atualmente, o maior mercado deste tipo de cirurgia no mundo, superando os Estados Unidos, que lideravam o ranking de cirurgias para fins estéticos. De acordo com a Revista Veja ${ }^{15}$, citando como fonte a Sociedade Brasileira de Cirurgia Plástica, em 2000,

“(...) 350.000 pessoas se submeteram a pelo menos um procedimento cirúrgico com finalidade estética. Fazendo as contas, isso significa que, em cada grupo de 100.000 habitantes, 207 pessoas foram operadas em 2000. Os Estados Unidos, tradicionais líderes do ranking, registraram 185 operados por 100.000 habitantes no mesmo ano. ${ }^{16}$

Segundo pesquisa do IBOPE (Instituto Brasileiro de Opinião Pública e Estatística), encomendada pela Associação Brasileira de Cirurgia Plástica, tivemos, em 2009, 443.145 cirurgias para fins estéticos realizadas, ou seja, 233 para cada 100 mil. O gráfico 7 indica a evolução do número de cirurgias plásticas realizadas no Brasil.

${ }^{12}$ Dados divulgados pela Revista VEJA, n. 34, p. 73.

${ }^{13}$ VIEIRA, Adriana Carvalho Pinto; CORNÉLIO, Adriana Regia. Produtos light e diet: o direito a informação ao consumidor. Jus Navigandi, Teresina, ano 9, n. 530, 19 dez. 2004. Disponível em: <http://jus2.uol.com.br/doutrina/texto.asp?id=6066>. Acesso em: 19 mar. 2007.

${ }^{14}$ O Estado de São Paulo, Suplemento Franquias, 14/07/98.

15 Revista Veja 17/08/2001 
Indústria da beleza: uma abordagem sócio-antropológica do culto ao corpo na cultura contemporânea

Há, atualmente, 6.000 cirurgiões plásticos no país, mas apenas $50 \%$ têm o título de Especialista, isto é, a habilitação para realizar a cirurgia. Das cirurgias realizadas no Brasil, $80 \%$ têm finalidade estética, enquanto apenas $20 \%$ são reparadoras, isto é, têm uma relação direta com a saúde.

As mulheres, mais que os homens, sempre procuraram esse tipo de intervenção cirúrgica. Recentemente, a diferença na distribuição do número de cirurgias realizadas por sexo tem diminuído. Se nos primeiros anos da década de 90 a proporção era de $85 \%$ de mulheres e $15 \%$ de homens, atualmente, ela é de $70 \%$ de mulheres e $30 \%$ homens. Nas mulheres predominam as intervenções na mama, abdômen e face; nos homens: barriga, pálpebra e ginecosmatra (retirada de mamas). ${ }^{17}$

O crescimento da indústria da moda é outro indicador da obsessão contemporânea pelos cuidados com a beleza e apresentação corporais. A explosão dos cursos de graduação em moda no país (vide gráfico 8), bem como o impacto e repercussão dos eventos do setor, a exemplo da São Paulo Fashion Week, testemunham a expansão da preocupação com a moda no interior da vida social. Para se ter uma idéia da importância econômica da SP Fashion Week, vale lembrar que ela impulsiona negócios na cadeia têxtil, no varejo, em serviços e em exportações. Só em espaço na mídia a SPFW movimenta mais de R 600 milhões por ano e cada edição do evento está orçada em $R \$ 6$ milhões. Diferentemente de outras semanas de moda - como a de Paris ou Londres, em que é preciso gastar algo em torno de Us\$ 130 mil, entre aluguel do espaço e profissionais para fazer a montagem das salas de desfile - a semana de moda de São Paulo é totalmente patrocinada, viabilizando a participação de marcas estilistas menores e sem recursos financeiros. Com isto, o evento é dinamizado, fazendo circular diariamente algo em torno de 20 mil pessoas no Pavilhão da Bienal durante a semana de desfiles. ${ }^{18}$

Vestir o corpo é um aspecto universal da experiência humana e não há registros de culturas que não tenham esta prática como regra social. De alguma maneira, o nu é trabalhado culturalmente, seja com pedras, pinturas, tatuagens ou tecidos. Este dado cultural universal está associado ao fato de que cobrir o corpo constitui-se num dos meios pelos quais o mesmo se torna social e assume uma identidade, estando pronto para a cena social, isto é, aceitável, respeitável, desejável, enfim, adequado.

E vestir-se, assim como outros elementos da cultura, como comunicar-se ou alimentar-se, requer um aparato de técnicas e habilidades que são socialmente aprendidas. Como aponta Entwistle (2000):

17 Informações fornecidas pela Assessoria de imprensa da Sociedade Brasileira de Cirurgia Plástica.

18. As informações sobre a SPFW foram retiradas da Revista FORBES Brasil, ano 7, n⿳o 148, janeiro/2007. 
“(...) vestir-se é uma prática constante, que requer conhecimento, técnicas e habilidades, desde aprender a amarrar os cordões dos sapatos $e$ abotoar os botões, até compreender as cores, as texturas e estampas, até combiná-las para que se adequem aos nossos corpos e vidas. (tradução livre).

Vestir, então, envolve normas culturais e expectativas em relação ao corpo, podendo, neste sentido, ser entendido como técnica corporal, tal como define Marcel Mauss. Ou seja, ampliando as idéias seminais do antropólogo francês, podemos pensar o vestir como um tipo de técnica corporal, uma vez que envolve práticas socialmente constituídas e aprendidas, porém executadas pelos indivíduos em busca de "construir seu corpo", ao evidenciar ou omitir uma de suas partes e torná-lo o mais aceitável/adequado ou agressivo/transgressor possível. Em resumo, o ato de vestir-se realiza-se dentro das limitações de uma cultura e suas normas, em busca de satisfazer as expectativas com relação ao que se aceita como um "corpo vestido".

O crescimento da indústria da beleza - envolvendo, entre outros setores de atividade, cosméticos, cirurgias plásticas e moda - além de estimular e respaldar práticas corporais, consiste num forte indicativo da centralidade que o culto ao corpo vem assumindo na cultura contemporânea, cada vez mais difícil de ser lida e interpretada. Retomando o princípio sócio-antropológico de que o corpo é signo maior das representações coletivas, buscamos compreender esta obsessão pela construção da aparência como estratégia de construção de identidade, numa sociedade em que cada vez mais a fragmentação e a efemeridade tomam lugar de referências anteriormente um pouco mais fixas e estáveis. Diante da complexidade dos nexos da relação entre as esferas econômica e o simbólica, muitas perguntas ainda permanecem à espera de respostas um pouco mais definitivas. A única certeza da qual podemos partir é a de que o desvendar destes nexos constitui-se numa das chaves mais esclarecedoras para leitura e compreensão da cultura contemporânea.

\section{Gráficos. Anexo I}

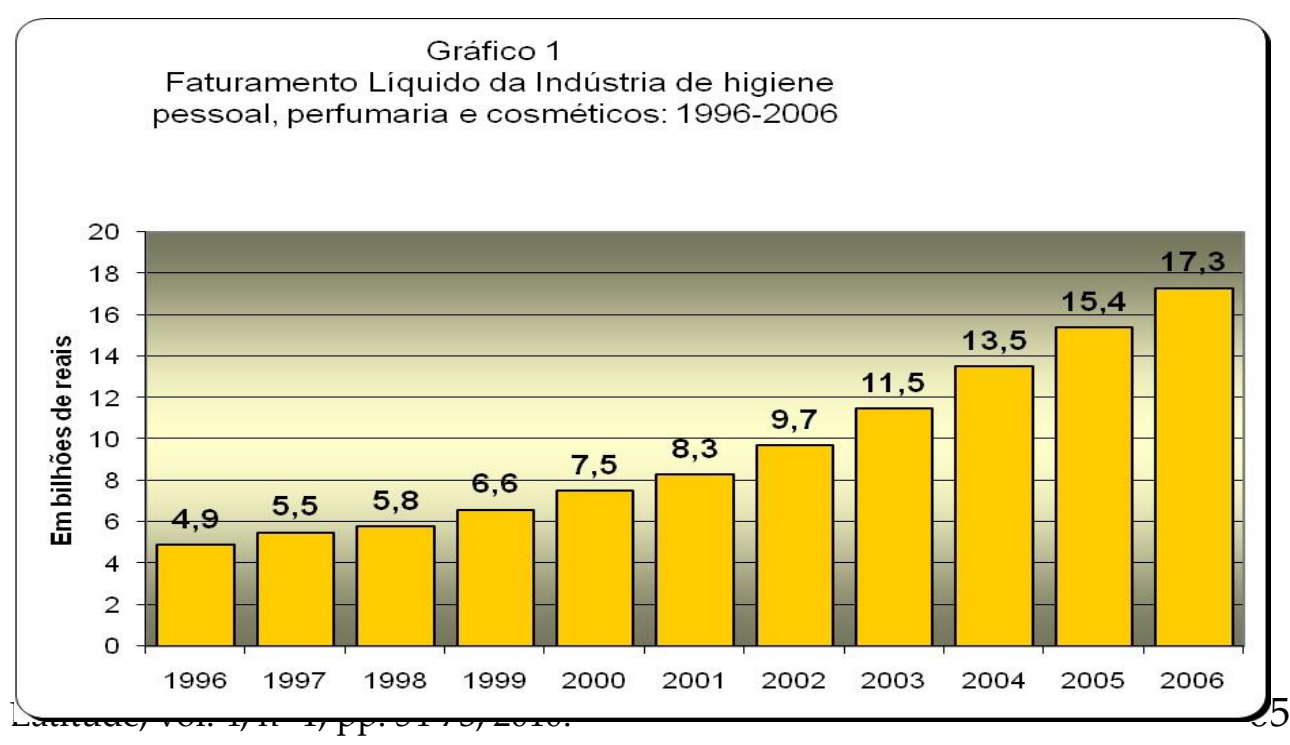


Indústria da beleza: uma abordagem sócio-antropológica do culto ao corpo na cultura contemporânea

Fonte: ABIHPEC/SIPATESP, 2007

Gráfico 2 - Crescimento do \% do PIB da Indústria total e da indústria de higiene pessoa, perfumaria e cosméticos (1996-2005)

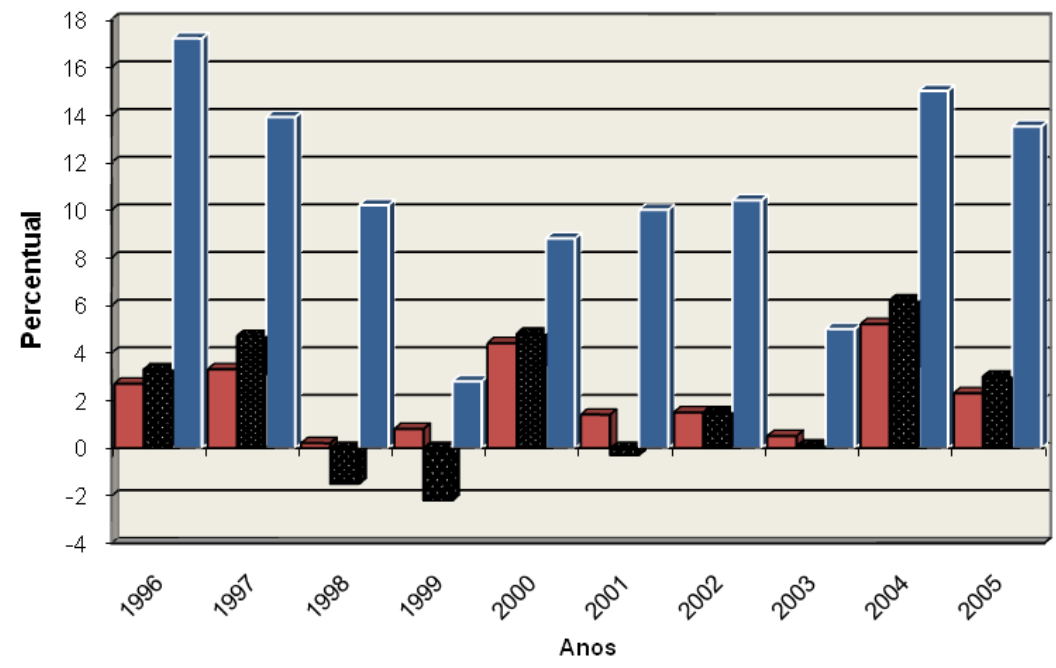

aPIB Indústria Geral - Higiene pessoal, perfumaria e cosméticos

Fonte: DEPEA - Departamento de Documentações, Pesquisas e Avaliações. FIESP/CIESP. 


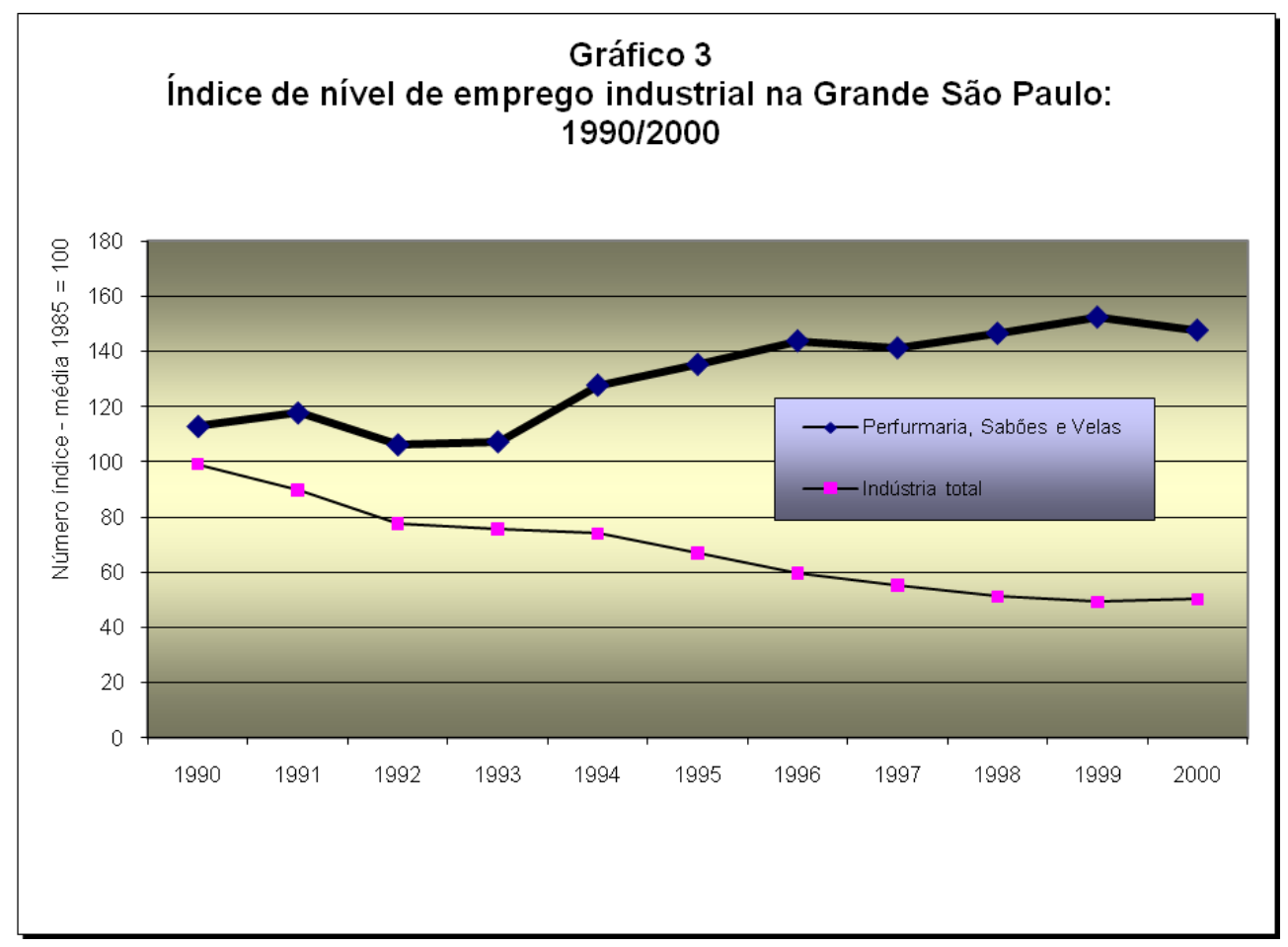

Fonte: Informe publicitário ABIHPEC/SIPATESP, jan/dez de 1997 e Relatório SIPATESP dez/2000. 
Indústria da beleza: uma abordagem sócio-antropológica do culto ao corpo na cultura contemporânea

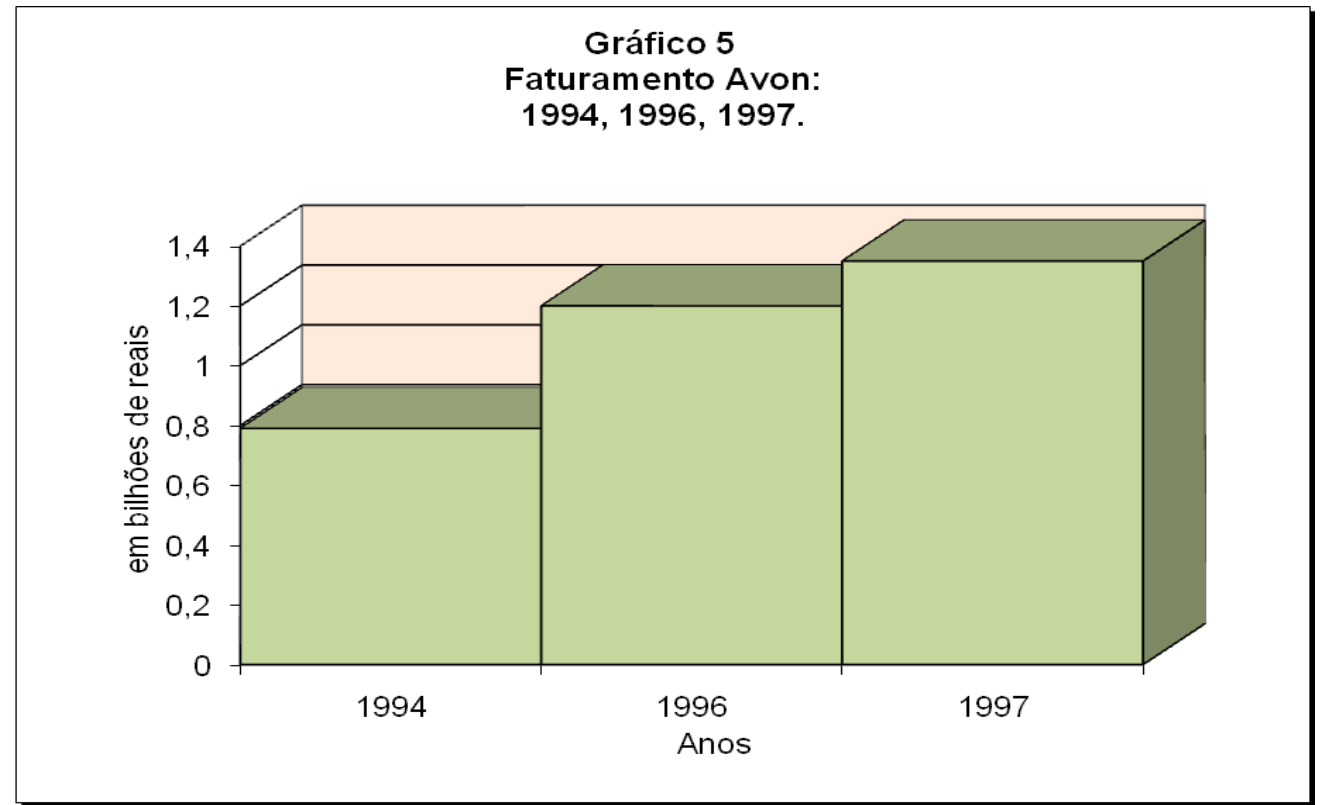

Fonte: Folha de São Paulo - Caderno Negócios - 11/08/1997. 


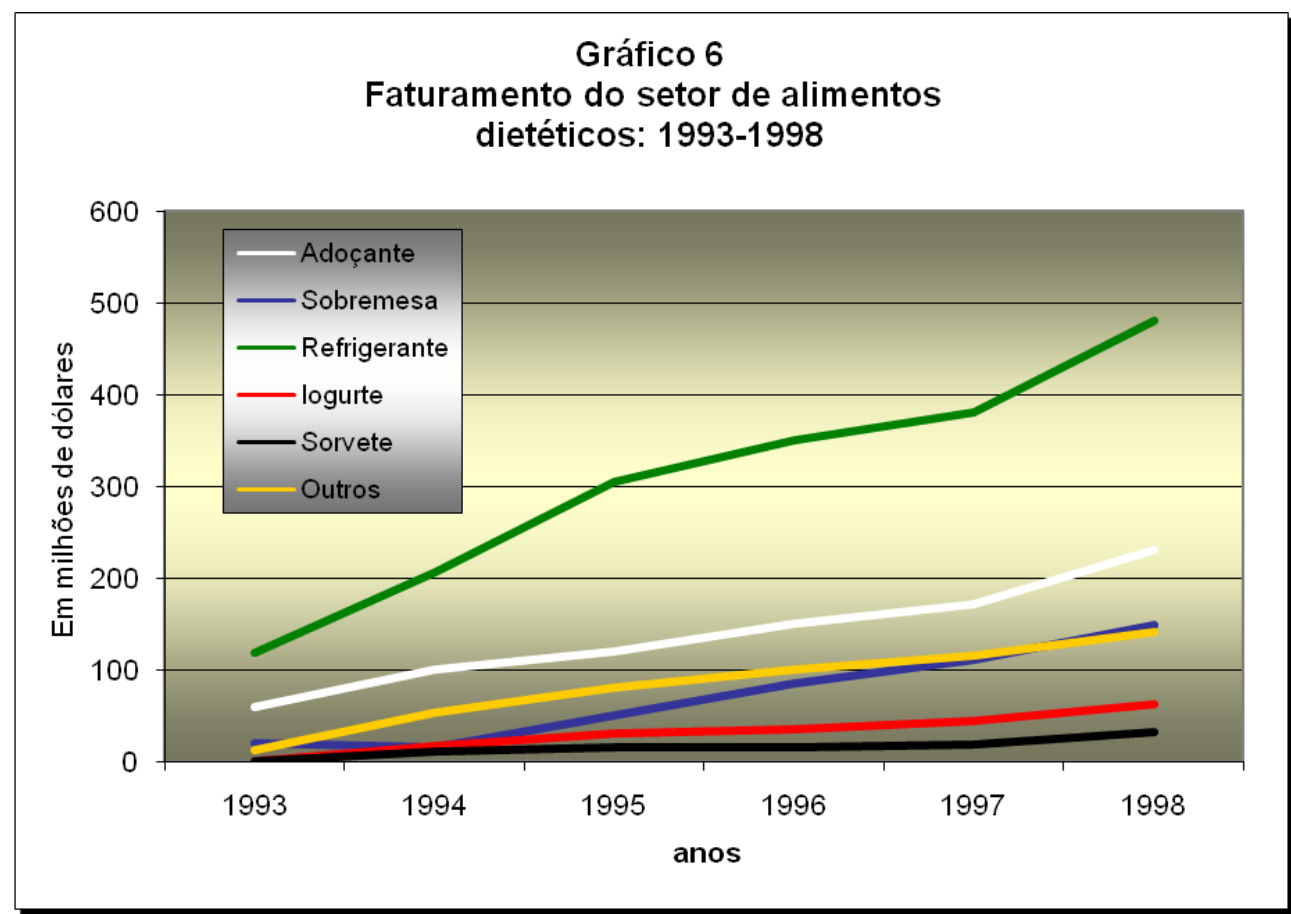

Fonte: ABIAD, 2000 
Indústria da beleza: uma abordagem sócio-antropológica do culto ao corpo na cultura contemporânea

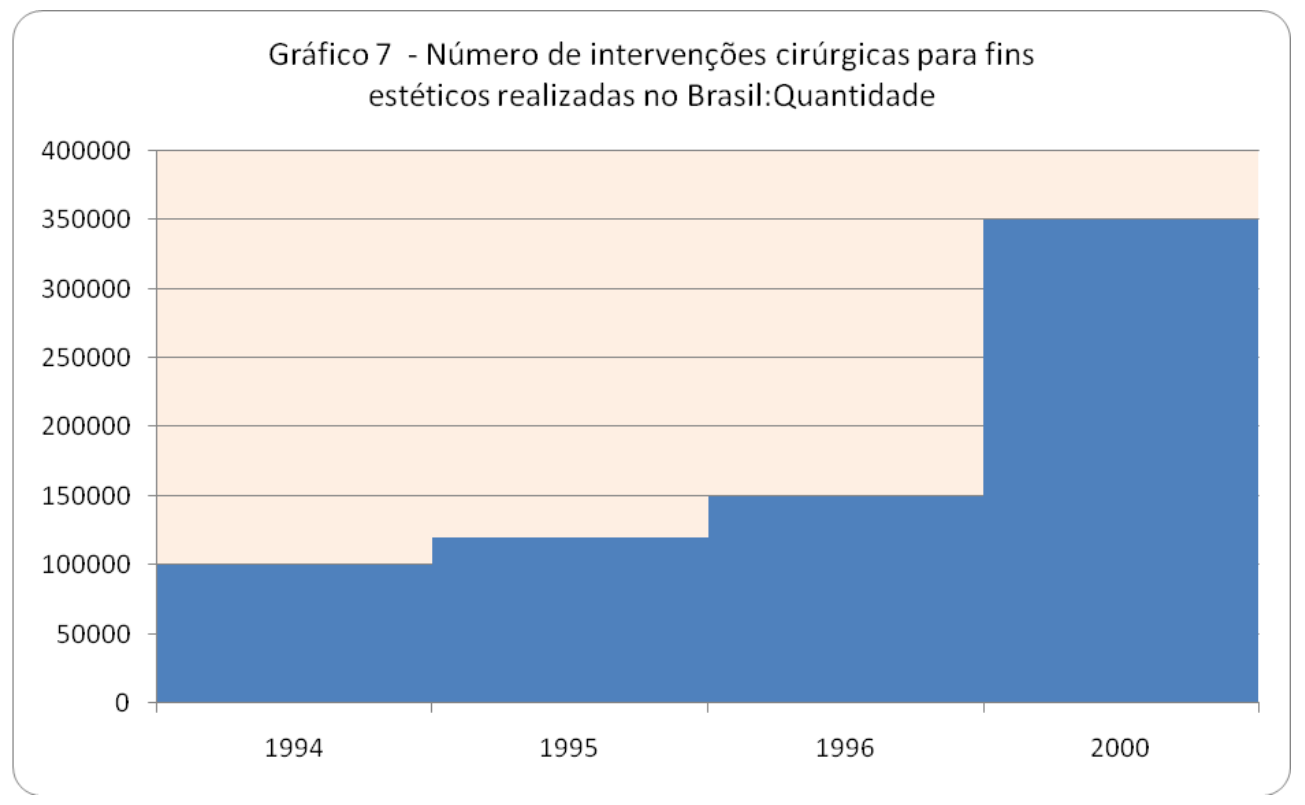

Fonte: Assessoria de Imprensa - Sociedade Brasileira de Cirurgia Plástica. 


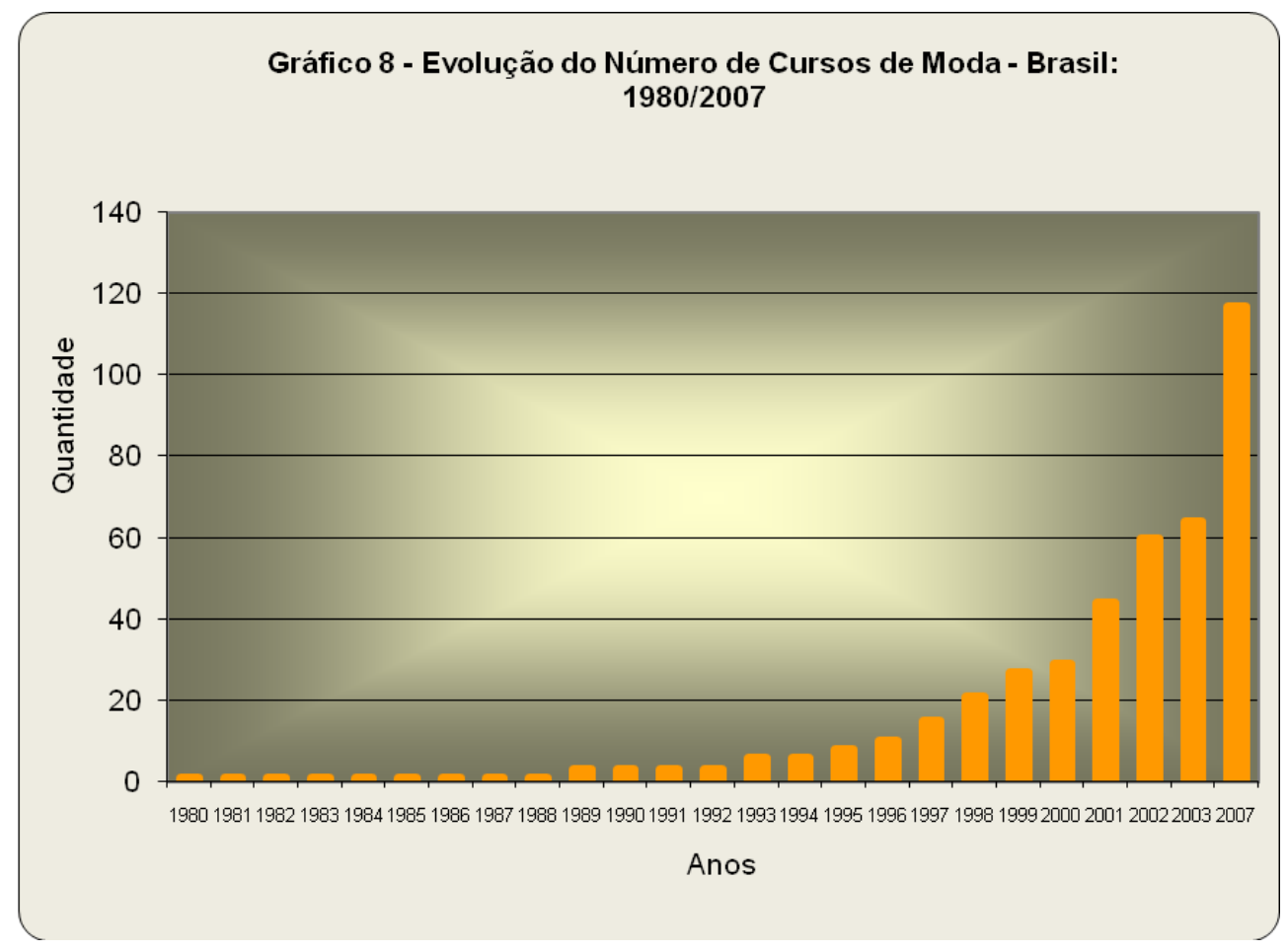

Fonte: INEP

\section{Bibliografia}

CASTRO, Ana Lúcia (2007) Culto ao corpo e sociedade: mídia, estilo de vida e cultura de consumo. São Paulo: Ed. Annablume,

CASTRO, Ana Lúcia (1998) "Culto ao corpo, modernidade e mídia". Lecturas: educación fisica y desportes, año 3, no 9, Buenos Aires.

BARTHÉLEMY, D. et.col. "Problemas: a emergência do indivíduo". In: História da vida privada:da europa feudal à renascença. São Paulo, Cia das Letras, 1992..(p. 515-599)

BOURDIEU, Pierre (1982) A economia das trocas simbólicas. São Paulo. Ed. Perspectiva.

Taurus, 1988

1988) La distinción: critérios y bases sociales del gusto. Madrid,

(2003) "Culto ao corpo e sociedade: mídia, cultura de consumo e estilos de vida". São Paulo: AnnaBlume. 
Indústria da beleza: uma abordagem sócio-antropológica do culto ao corpo na cultura contemporânea

CORBIN, Alain: "Bastidores: o segredo do indivíduo". In: História da vida privda: Da revolução francesa à primeira guerra. São Paulo, Cia das Letras, 1992.(p. 419-501)

De CERTEAU (1994) Michel A invenção do cotidiano: artes de fazer. Rio de Janeiro:Vozes.

DURKHEIM, Èmile (1984) "Algumas formas primitivas de classificação". In:RODRIGUES, J. (org). Émile Durkheim, São Paulo: Ática.

DOUGLAS, Mary (1976) Pureza e perigo. São Paulo: Perspectiva.

DOUGLAS, Mary. \& ISHWWOOD, Baron (2004) O mundo dos bens: para uma antropologia do consumo, Rio de Janeiro: Ed. UFRJ.

DWECK, Ruth Helena (1999) “A beleza como variável econômica: reflexo nos mercados de trabalho e de bens e serviços". Texto para discussão, no ${ }^{\circ}$ 618, IPEA: Rio de Janeiro.

ELIAS, Norbert A sociedade dos indivíduos. Rio de Janeiro, Jorge Zahar Ed., 1994.

ENTWISTLE, Joanne (2000). The fashioned body: fashion, dress and modern social theory. Oxford: Polity Press.

FEATHERSTONE, Mike (1992) The body: social process and cultural theory. London: Sage.

FEATHERSTONE, Mike Cultura de consumo e pós-modernismo. São Paulo, Studio Nobel, 1995.

FOUCAULT, Michel (1985) “O cuidado de si". In: História da sexualidade. Rio de Janeiro: Graal, vol.3.

FOUCAULT, Michel (1979) Microfísica do poder. Rio de Janeiro: Graal.

GARCIA, Renato (2005)“Internacionaliação comercial e produtiva da indústria de cosméticos: desafios competitivos para empresas brasileiras". São Paulo. Revista Produção, vol. 15, no 2, 2005.

GIDDENS, Anthony (1997). Modernidade e identidade pessoal, Oeiras/Portugal, Celta Editora.

GEERTZ, Clifford (1978) A interpretação das culturas. Rio de Janeiro: Zahar Editores.

HALL, Stuart (2000) A identidade cultural na pós-modernidade.Rio de Janeiro: Ed. DP\&A. 
LIPOVETSKY, Gilles (1999) O império do efêmero: a moda e seu destino nas sociedades modernas. São Paulo: Cia das Letras.

MAUSS, Marcel. (2003) "As Técnicas corporais". In: Sociologia e Antropologia. São Paulo: CosacNaify.

MIRA, Maria Celeste (1994) “O global e o local: mídia, identidades e usos da cultura". Revista Margem. EDUC/PUC-SP, no. 3, dez.

ORTIZ, Renato (1994) Mundialização e cultura. São Paulo: Brasiliense, 1994.

PROST, A. “Fronteiras e Espaços do privado. In: ARIÈS, P. \& DUBY, G. História da Vida Privada: da primeira guerra aos nossos dias. São Paulo, Cia das Letras, 1992. (p.9411)

ROBINS, Kevin (1991) "Tradition and translation: national culture. In its global context". In: CORNER, J. and HARVEY, S. (orgs.) Enterprise and Heritage: crosscurrents of national culture. Londres: Routledge.

ROUANET, Sérgio Paulo (2003) “O homem-máquina hoje”. IN: NOVAES, Adauto: O homem-máquina: a ciência manipula o corpo. São Paulo: Cia das Letras.

SIMMEL, Georg (1999) “La mode”, Philosophie de la modernité. La femme, la ville, l'individualisme. Paris: Payot.

TURNER, Bryan S (1989). El cuerpo y la sociedad: exploraciones en teoria social. México: Ed. Fondo de Cultura Económica

VEBLEN, Torstein (1983) A teoria da classe ociosa: um estudo econômico das instituições. São Paulo: Abril Cultural. (Col. Os economistas)

WILSON, Elizabeth (1989) Enfeitada de sonhos. Lisboa, Ed. 70.

WILLIAMS, Raymond (1979) Marxismo e literatura. Rio de Janeiro: Zahar. 